\title{
BMJ open Number and burden of cardiovascular diseases in relation to health-related quality of life in a cross-sectional population-based cohort study
}

\author{
Therese Djärv, Anna Wikman, Pernilla Lagergren
}

To cite: Djärv T, Wikman A, Lagergren $P$. Number and burden of cardiovascular diseases in relation to healthrelated quality of life in a cross-sectional populationbased cohort study. BMJ Open 2012;2:e001554. doi:10.1136/bmjopen-2012001554

- Prepublication history for this paper are available online. To view these files please visit the journal online (http://dx.doi.org/10.1136/ bmjopen-2012-001554).

Received 24 May 2012 Accepted 28 September 2012

This final article is available for use under the terms of the Creative Commons Attribution Non-Commercial 2.0 Licence; see http://bmjopen.bmj.com

Department of Molecular Medicine and Surgery, Karolinska Institutet, Stockholm, Sweden

Correspondence to Dr Therese Djärv; therese.djarv@ki.se

\section{ABSTRACT}

Objectives: To clarify whether a greater number of cardiovascular diseases or a larger burden of disease are associated with poorer health-related quality of life (HRQoL) in an unselected general population.

Design: A population-based cross-sectional postal survey.

Settings: A random sample of the Swedish general population aged $40-79$ years matched for national distributions of age, gender and region.

Participants: Out of 6969 eligible individuals, 4910 (70.5\%) participated.

Primary and secondary measures: To create a reference database for $\mathrm{HRQ}$ oL outcomes in the general population. To assess certain diseases and their relation to HRQoL.

Methods: Predefined cardiovascular diseases and HRQoL were assessed from validated questionnaires (EORTC QLQ-C30). Aspects of HRQoL included in the analyses were global quality of life, physical function, role function, emotional function, fatigue and dyspnoea. Individuals were categorised into: 'good function' versus 'poor function' and 'no or minor symptoms' versus 'symptomatic'. Multivariable logistic regression calculated OR with $95 \% \mathrm{Cl}$ for poor $\mathrm{HRQ}$ oL The exposures were the number of cardiovascular diseases and the subjective disease burden.

Results: Out of the 4910 participants, 1358 (28\%) reported having a cardiovascular disease and hypertension was most common. Reporting a greater number of cardiovascular diseases was associated with an increased risk of poor HRQoL, especially regarding dyspnoea. The OR for symptomatic dyspnoea was 1.37 (95\% Cl 1.08 to 1.74$)$ for participants with one cardiovascular disease, $4.81(95 \% \mathrm{Cl} 3.24$ to 7.13$)$ for two diseases and $4.18(95 \% \mathrm{Cl} 2.24$ to 7.80$)$ for those with three or more cardiovascular diseases. Among the 271 participants who assessed their cardiovascular disease burden as major, the highest risk for poor HRQoL was found for physical function (OR 6.18, $95 \% \mathrm{Cl} 3.72$ to 10.30 ).

Conclusions: Increased number of cardiovascular diseases and a greater burden of disease are generally associated with poorer HRQoL in people with cardiovascular disease from an unselected population.

\section{ARTICLE SUMMARY}

Article focus

- To clarify if people living in the general population have affected health related quality of life.

Key messages

- Increased number of cardiovascular diseases and a greater burden of disease are associated with poorer HRQoL (in people with cardiovascular disease from an unselected population).

Strengths and limitations of this study

- A large population-based design, well-validated commonly used questionnaires.

- Cross-sectional design, self-reported cardiovascular diseases.

\section{INTRODUCTION}

Cardiovascular diseases are followed by a lifelong risk of morbidity and impaired daily activities. $^{1-3}$ Therefore, health-related quality of life (HRQoL) has gained ground as a primary outcome when measuring the impact of disease or effect of treatment. ${ }^{4}$ Patients with cardiovascular disease report poorer HRQoL than the general population, but the available literature is rarely population based ${ }^{5-9}$ and only few studies based on unselected general populations are available. ${ }^{6}$ Moreover, many patients have more than one cardiovascular disease and the experience of burden of disease might differ among patients. It is not known if multiple cardiovascular conditions have a synergetic negative effect on HRQoL or if the subjective experience of cardiovascular disease affects HRQoL. ${ }^{10-12}$ Previous research in this field has mainly evaluated one separate diagnosis in a selected group of patients, but the associations between multiple cardiovascular diagnoses and HRQoL, especially in the unselected general population, have only scarcely been studied before. Such information would be valuable for planning clinical 
care and interventions that aim to improve patients' HRQoL. Therefore, this study aimed to assess the influence of the number of cardiovascular diseases and experienced burden of cardiovascular diseases in relation to the risk of poor HRQoL in the unselected general population. Our hypotheses are that there is an association between a higher number of diseases or a major burden from any cardiovascular disease and poor HRQoL.

\section{METHODS}

\section{Design and settings}

A population-based, cross-sectional survey was conducted in Sweden between April and June 2008. Eligible for inclusion in the study were all individuals aged 40-79 years within the Swedish Register of the Total Population, which includes up-to-date, complete information about dates of birth, migrations and deaths for all residents in Sweden since 1968. Of those who were eligible to participate a random sample was drawn by Statistics Sweden, with the purpose of creating a reference database for HRQoL. The size of the sample was based on power calculations for subgroups such as age and gender. Further, the age and gender of the invited individuals were matched against distributions of age and gender corresponding to Sweden's general population within this age range. A self-completion postal questionnaire, assessing socio-demographic variables, comorbidities, lifestyle factors, cardiovascular diseases and HRQoL, was sent to all eligible individuals. By completing and returning the questionnaires, participants consented to their data being used for research purposes. Non-responders were sent up to two reminder letters. The study was approved by the Regional Ethics Board in Stockholm, Sweden.

\section{Socio-demography, comorbidity and lifestyle factors}

Information on age, sex, education level, tobacco smoking status, physical activity and comorbidities was collected from the questionnaire. Comorbidities were defined as the following diagnoses given by a physician: asthma, chronic obstructive pulmonary disease, diabetes, rheumatoid arthritis, osteoarthritis, previous stroke, kidney failure under dialysis, chronic pain, depression under treatment, current cancer or any other specified disease. Our main reason for classifying previous stroke as a comorbidity rather than a primary cardiovascular disease is that there is a risk that participants with a previous stroke may be more likely to report HRQoL based on the stroke than on their other cardiovascular diseases.

\section{Cardiovascular disease exposure}

Angina, atrial fibrillation, hypertension, heart failure and previous myocardial infarction were selected to represent cardiovascular diseases. Participants reporting that at least one of the cardiovascular diagnoses had been given by a physician were categorised as having 'cardiovascular disease', whereas participants who responded 'no' to all questions about cardiovascular diseases were categorised as having 'no cardiovascular disease'. Those who reported having a cardiovascular disease were asked to rate their perceived burden from each of the specific diseases by answering the question 'To what degree does your disease affect your health?'. The responses were scored on a 4-point scale: 'not at all', 'a little', 'quite a bit' or 'very much'. Participants who responded 'quite a bit' or 'very much', for at least one cardiovascular disease were categorised in the 'major burden' group; others were put in the 'minor burden' category.

\section{Health-related quality-of-life outcome}

HRQoL was assessed with the QLQ-C30, developed by the European Organisation for Research and Treatment of Cancer. ${ }^{13}$ The QLQ-C30 is a 30-item questionnaire, including one global quality-of-life scale, five functional scales (physical, role, social, emotional and cognitive function), three symptom' scales (fatigue, nausea and pain) and six single items (sleep problems, appetite loss, dyspnoea, diarrhoea, constipation and financial problems). This questionnaire was originally designed to assess HRQoL in cancer patients, but has previously been used in general population studies of HRQoL. ${ }^{14}$

In this study, six HRQoL outcomes were selected a priori for analysis: global quality of life, physical function, role function, emotional function, fatigue and dyspnoea. The selection was made to reduce multiple testing and was based on symptoms considered most

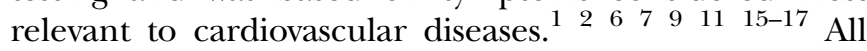
items corresponded to participants' experiences during the past week and were rated on a 4-point scale: 'not at all', 'a little', 'quite a bit' and 'very much'. The response alternatives on the global quality-of-life scale ranged from 1 'very poor' to 7 'excellent'. All responses were dichotomised into 'good' versus 'poor' function and 'no or minor symptoms' versus 'symptomatic'. At least one response of 'quite a bit' or 'very much' to an item within a scale categorised the participant into 'poor' function or 'symptomatic'. Otherwise, the participant was categorised as having 'good' function or 'no or minor symptoms'. Missing responses were handled according to recommendations by the questionnaire developers. If information was missing on more than half of the items within a scale or on a single item, the participant was not included in the analyses of that specific scale or item but still included on all other scales or items. For the global quality-of-life scale, at least one response of 1-4 to an item within the scale categorised the participant as having 'poor' global quality of life. Otherwise, the participant was categorised as having 'good' global quality of life. These binary cut-offs were used to aid interpretation of HRQoL assessment in clinical practise. These were based on clinical experience and intended to represent a level that would be likely to capture the attention of a clinician in clinical practise. 


\section{Statistical analysis}

Standard descriptive statistics were used to describe the sample characteristics. Statistically significant differences in sample characteristics between participants with and without cardiovascular diseases were tested using the $\chi^{2}$ test. To examine the associations between number of cardiovascular diseases and burden of disease, and the risk of poor HRQoL, OR with 95\% CI were calculated using multivariable logistic regression. In multivariable modelling, adjustments were made for age $(40-50,51-60$, 61-70 and 71-79), sex, education level $(<9,10-12$ and $>12$ years), tobacco-smoking status (ever smoked and never smoked), physical activity ( $<30 \mathrm{~min}$ at least once weekly and $>30$ min once weekly) and comorbidity (yes and no). A weighting factor was applied to ensure that the characteristics of the study sample conformed to independently estimated national distributions by age, sex and region. ${ }^{18}$ The statistical package STATA V.9.2 for windows (STATA Corp, College Station, Texas, USA) was used for all data analyses.

\section{RESULTS}

\section{Study participants}

Among the 7002 randomly selected individuals, 33 had died or emigrated, leaving 6969 eligible for the study. Of these, 4910 ( $70.5 \%$ of all those eligible) participated. Among the non-participants, 2001 (28.7\%) did not respond and $58(0.8 \%)$ had unknown address or someone other than the invited person responded. Non-responders did not differ from responders in terms of socio-demographic characteristics. The weighted sample characteristics are presented in table 1. Of the participants, 1358 (28\%) reported at least one predefined cardiovascular disease. The group with cardiovascular disease also had a lower educational level, were less prone to exercise regularly, and suffered more often from comorbidities compared to the group without cardiovascular disease (all differences were significant at $\mathrm{p}<0.001)$. No statistically significant difference was found for tobacco smoking (table 1). The most common single cardiovascular disease was hypertension $(\mathrm{n}=901,18 \%)$, followed by atrial fibrillation $(n=75,2 \%)$, angina $(n=59$, $1 \%)$, previous myocardial infarction $(\mathrm{n}=57,1 \%)$ and heart failure $(\mathrm{n}=11<1 \%)$. Of the total sample, $255(5 \%)$ reported multiple cardiovascular diagnoses.

\section{Cardiovascular disease and $\mathrm{HRQ} \mathrm{OL}$}

Poor HRQoL was almost twice as common in the cardiovascular disease group compared with those without cardiovascular disease (table 2). Among the cardiovascular

Table 1 Characteristics of the 4910 study participants, randomly selected from the Swedish general population. Frequency weighted for age and sex to match the national distribution in Sweden

\begin{tabular}{|c|c|c|c|}
\hline & $\begin{array}{l}\text { Total sample } \\
\text { Number (\%) }\end{array}$ & $\begin{array}{l}\text { Participants without } \\
\text { cardiovascular disease* } \\
\text { Number (\%) }\end{array}$ & $\begin{array}{l}\text { Participants with } \\
\text { cardiovascular disease* } \\
\text { Number (\%) }\end{array}$ \\
\hline Total & $4910(100)$ & $3552(72)$ & $1358(28)$ \\
\hline \multicolumn{4}{|l|}{ Sex } \\
\hline Male & $2441(50)$ & $1762(50)$ & $679(50)$ \\
\hline Female & $2469(50)$ & $1791(50)$ & $678(50)$ \\
\hline \multicolumn{4}{|c|}{ Age groups (years) } \\
\hline $40-50$ & $1614(33)$ & $1435(40)$ & 179 (13) \\
\hline $51-60$ & $1368(28)$ & $1060(30)$ & $308(23)$ \\
\hline $61-70$ & $1241(25)$ & $736(21)$ & 505 (37) \\
\hline 71-79 & $687(14)$ & $321(9)$ & $366(27)$ \\
\hline \multicolumn{4}{|c|}{ Years of formal education } \\
\hline$\leq 9$ & $1691(34)$ & $1028(29)$ & $663(49)$ \\
\hline $10-12$ & $2057(42)$ & $1614(45)$ & $443(33)$ \\
\hline$>12$ & $1010(21)$ & $808(23)$ & $202(15)$ \\
\hline Missing & $114(2)$ & $77(2)$ & $37(3)$ \\
\hline \multicolumn{4}{|c|}{ Tobacco smoking status } \\
\hline Never & $2447(50)$ & $1777(50)$ & $671(49)$ \\
\hline Ever & $2310(47)$ & $1678(47)$ & $632(47)$ \\
\hline Missing & $153(3)$ & $97(3)$ & $55(4)$ \\
\hline \multicolumn{4}{|c|}{ Regular physical exercise (>30 min at least once weekly) } \\
\hline Yes & $4411(90)$ & $3249(91)$ & $1162(86)$ \\
\hline No & $418(9)$ & $253(7)$ & $165(12)$ \\
\hline Missing & $81(2)$ & $50(1)$ & $31(2)$ \\
\hline \multicolumn{4}{|c|}{ Comorbidity } \\
\hline None & $2659(54)$ & $2235(63)$ & $424(31)$ \\
\hline Yes & $1582(32)$ & $972(27)$ & $609(45)$ \\
\hline Missing & $569(12)$ & $345(10)$ & $325(24)$ \\
\hline
\end{tabular}


Table 2 Occurrence of cardiovascular disease and risk of poor health-related quality of life (HRQLL) assessed with European Organisation for Research and Treatment of Cancer QLQ-C30 and presented as OR with 95\% Cl

\begin{tabular}{|c|c|c|c|c|}
\hline \multirow[b]{3}{*}{ HRQoL aspects* } & \multicolumn{4}{|c|}{ Cardiovascular diseases $†$} \\
\hline & \multicolumn{2}{|c|}{$\begin{array}{l}\text { None } \\
3552(72)\end{array}$} & \multicolumn{2}{|l|}{$\begin{array}{l}\text { At least one } \\
1358(28)\end{array}$} \\
\hline & Number (\%) & & Number (\%) & OR (95\% Cl)‡ \\
\hline Poor global quality of life & $414(12)$ & Reference & $250(18)$ & 1.45 (1.06 to 1.97$)$ \\
\hline Poor physical function & $946(27)$ & Reference & $675(50)$ & 1.77 (1.36 to 2.32$)$ \\
\hline Poor role function & $325(9)$ & Reference & $208(15)$ & $1.91(0.97$ to 3.76$)$ \\
\hline Poor emotional function & $587(17)$ & Reference & $250(18)$ & $0.94(0.70$ to 1.26$)$ \\
\hline Symptomatic fatigue & $651(18)$ & Reference & $343(25)$ & 1.41 (1.07 to 1.86$)$ \\
\hline Symptomatic dyspnoea & $1040(29)$ & Reference & $628(46)$ & 1.69 (1.36 to 2.09$)$ \\
\hline
\end{tabular}

Frequency weighted for age and sex to match the national distribution in Sweden.

*Poor or symptomatic: At least one response of 'quite a bit' or 'very much' on an item within a scale (physical, role and emotional function,

fatigue and dyspnoea) or at least one response of 1-4 on one of the items in the Global quality-of-life scale.

†Cardiovascular disease: Angina, atrial fibrillation, heart failure, hypertension or earlier myocardial infarction.

$\ddagger$ Adjusted for age, sex, education, comorbidity, tobacco smoking and physical activity.

disease participants, about half-reported poor physical function and symptomatic dyspnoea, one-quarter reported symptomatic fatigue, and fewer than a sixth of participants reported poor global quality of life, poor emotional function and poor role function. Participants with cardiovascular disease had nearly double the risk of poor HRQoL on four of the six selected outcomes, compared to participants without cardiovascular disease. The highest OR was observed for physical function (OR $1.77,95 \%$ CI 1.36 to 2.32), followed by dyspnoea, and global quality of life, with the lowest OR observed for fatigue (OR 1.41, 95\% CI 1.07 to 1.86 ) (table 2). Surprisingly, no significant difference was observed on either role function (OR 1.91, 95\% CI 0.97 to 3.76) or emotional function (OR $0.94,95 \%$ CI 0.70 to 1.26 ) (table 2).

\section{Associations between separate cardiovascular diagnoses} and HRQOL

Compared to participants without cardiovascular disease, participants with hypertension did not show any significant increased risk for poor HRQoL (table 3). But participants with atrial fibrillation had an increased risk of having poor role function (OR 8.78, 95\% CI 1.24 to 62.01) and those with a previous myocardial infarction had about a twofold increased risk of poor physical function (OR 2.37, 95\% CI 1.31 to 4.28). Likewise, participants with angina were at an increased risk for dyspnoea

Table 3 Cardiovascular diagnosis and risk for poor health-related quality of life (HRQL) assessed with the European Organisation for Research and Treatment of Cancer QLQ-C30 and presented as OR with $95 \% \mathrm{Cl}$

\begin{tabular}{|c|c|c|c|c|c|}
\hline \multirow[b]{2}{*}{$\begin{array}{l}\text { HRQoL } \\
\text { aspects } ¥\end{array}$} & \multicolumn{5}{|c|}{ Cardiovascular diagnosis*, OR (95\% Cl)† } \\
\hline & $\begin{array}{l}\text { No cardiovascular } \\
\text { disease } \\
3552(72 \%)\end{array}$ & $\begin{array}{l}\text { Only } \\
\text { hypertension } \\
901(18 \%)\end{array}$ & $\begin{array}{l}\text { Only atrial } \\
\text { fibrillation } \\
75(2 \%)\end{array}$ & $\begin{array}{l}\text { Only previous } \\
\text { myocardial infarction } \\
57(1 \%)\end{array}$ & $\begin{array}{l}\text { Only angina } \\
59(1 \%)\end{array}$ \\
\hline $\begin{array}{l}\text { Poor global } \\
\text { quality of life }\end{array}$ & 1.00 (reference) & $1.24(0.85$ to 1.81$)$ & $1.06(0.51$ to 2.19$)$ & $0.89(0.26$ to 3.10$)$ & $2.09(0.85$ to 5.10$)$ \\
\hline $\begin{array}{l}\text { Poor physical } \\
\text { function }\end{array}$ & 1.00 (reference) & $1.33(0.96$ to 1.84$)$ & 1.97 (0.88 to 4.40$)$ & 2.37 (1.31 to 4.28$)$ & $4.83(2.22$ to 10.50$)$ \\
\hline $\begin{array}{l}\text { Poor role } \\
\text { function }\end{array}$ & 1.00 (reference) & 1.34 (0.65 to 2.79$)$ & $8.78(1.24$ to 62.01$)$ & $2.41(0.63$ to 9.26$)$ & Number too small \\
\hline $\begin{array}{l}\text { Poor emotional } \\
\text { function }\end{array}$ & 1.00 (reference) & $0.86(0.60$ to 1.23$)$ & 0.87 (0.36 to 2.10$)$ & $0.43(0.11$ to 1.71$)$ & $1.44(0.55$ to 3.78$)$ \\
\hline $\begin{array}{l}\text { Symptomatic } \\
\text { fatigue }\end{array}$ & 1.00 (reference) & $1.01(0.73$ to 1.41$)$ & 1.77 (0.60 to 5.23$)$ & $0.93(0.30$ to 2.92$)$ & $1.01(0.34$ to 2.99$)$ \\
\hline $\begin{array}{l}\text { Symptomatic } \\
\text { dyspnoea }\end{array}$ & 1.00 (reference) & $1.24(0.96$ to 1.59$)$ & 1.47 (0.59 to 3.62$)$ & $1.32(0.72$ to 2.42$)$ & $6.81(3.26$ to 14.24$)$ \\
\hline \multicolumn{6}{|c|}{$\begin{array}{l}\text { Frequency weighted for age and sex to match the national distribution in Sweden. } \\
\text { *Cardiovascular diagnosis: Answer 'Yes' to written question 'Have you been diagnosed with the following disease by a physician?' Due to } \\
\text { missing data, the percentages do not add up to } 100 \% \text {. In all, } 255 \text { persons had multiple diagnosis and is not included in the analysis above. } \\
\text { †Adjusted for age, sex, education, comorbidity, tobacco smoking and physical activity. } \\
\text { tPoor or symptomatic: At least one response of 'quite a bit' or 'very much' to an item within a scale (physical, role and emotional function, } \\
\text { fatigue and dyspnoea) or at least one response of } 1-4 \text { on one of the items in the global quality-of-life scale. }\end{array}$} \\
\hline
\end{tabular}


Table 4 Number of cardiovascular diseases and risk for poor health-related quality of life (HRQLL) assessed with the European Organisation for Research and Treatment of Cancer QLQ-C30 and presented as OR with 95\% Cl

\begin{tabular}{|c|c|c|c|c|}
\hline \multirow[b]{2}{*}{ HRQoL aspects $\ddagger$} & \multicolumn{4}{|c|}{ Number of cardiovascular diseases*, OR (95\% Cl)† } \\
\hline & $\begin{array}{l}\text { None } \\
3552(72 \%)\end{array}$ & $\begin{array}{l}\text { One } \\
1103(22 \%)\end{array}$ & $\begin{array}{l}\text { Two } \\
172(3 \%)\end{array}$ & $\begin{array}{l}\text { Three or more } \\
83(2 \%)\end{array}$ \\
\hline Poor global quality of life & 1.00 (reference) & $1.28(0.90$ to 1.81$)$ & 1.81 (0.95 to 3.42$)$ & 3.38 (1.84 to 6.21$)$ \\
\hline Poor physical function & 1.00 (reference) & $1.52(1.13$ to 2.04$)$ & 3.67 (2.45 to 5.48$)$ & $3.52(1.74$ to 7.10$)$ \\
\hline Poor role function & 1.00 (reference) & $1.70(0.79$ to 3.68$)$ & 2.71 (0.95 to 7.74$)$ & 3.16 (1.18 to 8.44$)$ \\
\hline Poor emotional function & 1.00 (reference) & $0.86(0.62$ to 1.20$)$ & $1.24(0.70$ to 2.20$)$ & 1.44 (0.79 to 2.64$)$ \\
\hline Symptomatic fatigue & 1.00 (reference) & 1.09 (0.80 to 1.49$)$ & 3.69 (2.32 to 5.87$)$ & 3.66 (1.87 to 7.18$)$ \\
\hline Symptomatic dyspnoea & 1.00 (reference) & 1.37 (1.08 to 1.74$)$ & 4.81 (3.24 to 7.13$)$ & 4.18 (2.24 to 7.80$)$ \\
\hline
\end{tabular}

Frequency weighted for age and sex to match the national distribution in Sweden.

${ }^{*}$ Cardiovascular disease: Angina, atrial fibrillation, heart failure, hypertension or earlier myocardial infarction. Due to missing data, the percentages do not add up to $100 \%$.

†Adjusted for age, sex, education, comorbidity, tobacco smoking and physical activity.

$\ddagger$ Poor or symptomatic: At least one response of 'quite a bit' or 'very much' to an item within a scale (physical, role and emotional function, fatigue and dyspnoea) or at least one response of 1-4 to one of the items in the global quality-of-life scale.

(OR 6.81, 95\% CI 3.26 to 14.24 ) and poor physical function (OR 4.83, 95\% CI 2.22 to 10.50). Heart failure could not be studied separately due to lack of power $(<1 \%$ reported only heart failure) .

\section{Association between number of cardiovascular diseases and HRQOL}

Of the total sample, 1102 (22\%) reported one cardiovascular disease, $172(3 \%)$ two and $83(2 \%)$ reported three or more cardiovascular diseases. An increased number of cardiovascular diseases were associated with an increased risk for poor HRQoL on all HRQoL aspects (table 4). Participants with three or more cardiovascular diseases were at a more than 4 times higher risk of symptomatic dyspnoea (OR 4.18, 95\% CI 2.24 to 7.80 ) and about a tripled risk of poor global quality of life, poor physical function, poor role function and fatigue (highest OR 3.66, 95\% CI 1.87 to 7.18 for fatigue to lowest for role function OR 3.16, 95\% CI 1.18 to 8.44) as compared with participants without cardiovascular disease. There was, however, no statistically significant association between number of cardiovascular diseases and impairments in emotional function (table 4).

\section{Association between the burden of cardiovascular disease and HRQOL}

The group of 271 (14\%) participants with cardiovascular disease reporting 'major burden' was at an increased risk of poor HRQoL compared with participants reporting 'minor burden'. The ORs ranged from 6.18 (95\% CI 3.72 to 10.30) for poor physical function, and in decreasing order, fatigue, dyspnoea, poor emotional function and poor global quality of life, with the lowest OR observed for poor role function (OR 2.06, 95\% CI 0.95 to 4.49) (table 5).

Table 5 Risk of poor health-related quality of life (HRQoL), assessed with the European Organisation for Research and Treatment of Cancer QLQ-C30, among participants with cardiovascular disease reporting major burden of disease, compared with people reporting minor burden, presented as OR with $95 \% \mathrm{Cl}$

\begin{tabular}{|c|c|c|c|c|}
\hline \multirow[b]{3}{*}{ HRQoL aspects $\dagger$} & \multicolumn{4}{|c|}{ Burden of any cardiovascular disease ${ }^{\star}$} \\
\hline & \multicolumn{2}{|c|}{$\begin{array}{l}\text { Minor burden } \\
1166(86 \%)\end{array}$} & \multicolumn{2}{|l|}{$\begin{array}{l}\text { Major burden } \\
192(14 \%)\end{array}$} \\
\hline & Number (\%) & OR (95\% Cl)‡ & Number (\%) & OR (95\% Cl)‡ \\
\hline Poor global quality of life & $171(15)$ & 1.00 (reference) & $80(42)$ & 2.09 (1.21 to 3.60$)$ \\
\hline Poor physical function & $515(44)$ & 1.00 (reference) & $160(83)$ & 6.18 (3.72 to 10.30$)$ \\
\hline Poor role function & $133(11)$ & 1.00 (reference) & $76(40)$ & 2.06 (0.95 to 4.49$)$ \\
\hline Poor emotional function & $174(15)$ & 1.00 (reference) & $77(40)$ & 2.78 (1.55 to 4.98$)$ \\
\hline Symptomatic fatigue & 226 (19) & 1.00 (reference) & $118(61)$ & 4.64 (2.73 to 7.88$)$ \\
\hline Symptomatic dyspnoea & $481(41)$ & 1.00 (reference) & $149(78)$ & 4.37 (2.54 to 7.49$)$ \\
\hline
\end{tabular}

Frequency weighted for age and sex to match the national distribution in Sweden.

“Minor burden: Participants reporting 'none' or 'a little' burden of any cardiovascular disease. Others are grouped as 'major burden'. Cardiovascular disease: Angina, atrial fibrillation, heart failure, hypertension or earlier myocardial infarction. Participants with multiple diagnosis (255).

†Poor or symptomatic: At least one response of 'quite a bit' or 'very much' on an item within a scale (physical, role and emotional function, fatigue and dyspnoea) or at least one response of 1-4 on one of the items in the global quality-of-life scale.

$\ddagger$ Adjusted for age, sex, education, comorbidity, tobacco smoking and physical activity. 


\section{DISCUSSION}

The key results of this study are the strong associations between the number of cardiovascular diseases and disease burden, and the risk of poor global quality of life, poor physical function, poor role function, fatigue and dyspnoea. Among separate cardiovascular diseases, the highest risk of poor HRQoL appeared to occur in patients with angina and atrial fibrillation. Hypertension was the most common disease, but was not associated with decreased HRQoL.

Strengths of the study include the population-based design with random selection of participants, the high participation rate, and the large sample size. Moreover, HRQoL was measured with a well-validated and extensively used questionnaire. Of note is that among participants, fewer women reported cardiovascular disease than men, a possible effect of gender bias in diagnoses of cardiovascular diseases in society in general.

Limitations include uncertainty about the accuracy of self-reporting including the patient's own experience of disease and lack of validation of cardiovascular diseases, and the amount of missing data for cardiovascular disease $(10 \%)$, and possible risk of higher nonparticipation among individuals with cardiovascular disease than among those without cardiovascular disease. Further, we lack information about time since diagnosis. It is possible that an association between cardiovascular disease and HRQoL varies with time since diagnosis. The number of participants with certain single cardiovascular diseases was limited, particularly those with heart failure, which reduced the statistical power to evaluate these conditions separately. Similarly, the findings of poor role function among the group with only atrial fibrillation has a wide CI and includes only a small number of participants, and therefore needs to be interpreted with caution. Nevertheless, the study revealed some strong effects that reached the level of statistical significance. In addition, the prevalence of cardiovascular diseases in the study cohort corresponds well with prevalence observed in the Swedish population, ${ }^{19}$ indicating validity and generalisability of the results to age groups included in the study. However, the HRQoL questionnaire used was constructed for, and has mainly been validated in, cancer patients and might not be an ideal measurement to assess HRQoL in people with cardiovascular disease. In using a potential nonsensitive measure of HRQoL the study may not be able to correctly determine the threshold for reporting poor HRQoL instead of good HRQoL associated with cardiovascular disease. Therefore, we chose cut-offs based on responses that would be likely to capture a clinician's attention, for example, a patient responding 'quite a bit' or 'very much' for a symptom or function, instead of using mean score differences between groups.

To the best of our knowledge, only one previous study has presented findings about HRQoL differences between people with and without cardiovascular disease in a random sample of a general population. In line with the present results, this study concluded that health state utility values differ (except for by age and gender) by history of cardiovascular disease including number of cardiovascular disease. Associations between cardiovascular disease and HRQoL have mainly been assessed using other designs. One hospital-based cross-sectional study assessed patients with an acute episode of coronary heart disease and compared their HRQoL to that of the Spanish general population. It showed that the coronary heart disease patients, especially the youngest patients, reported lower role function, more pain, poorer vitality and social functioning, than the general population. ${ }^{7}$ However, this study only included 132 patients and was performed during the acute phase of the disease. A study from the UK, set in two hospitals, compared HRQoL in patients 4 years after a myocardial infarction with population norms and found similar results. ${ }^{9} \mathrm{~A}$ study from the USA found an association between the number of comorbidities and poor HRQoL. ${ }^{20}$ Similarly, in a diabetic population, cardiovascular disease was found to have a negative effect on HRQoL. ${ }^{3}$ Thus, the results of the present study and the existing evidence suggest a substantial negative effect of cardiovascular disease on several aspects of HRQoL.

One biological explanation for poorer HRQoL among participants with a greater number of cardiovascular diseases is that each disease may result in a certain load of symptoms that, when experienced together, cause a negative synergetic effect on HRQoL. ${ }^{11}$ Another possible explanation is that patients with more cardiovascular diseases are more likely to have other unknown comorbidities than those we have assessed, or temporary diseases not captured by the questionnaire that may have an impact on HRQoL. However, our results were adjusted for other self-reported comorbidities (open question, free text response). The higher risk for poor HRQoL observed among participants with angina or atrial fibrillation may be due to the nature of these diseases. For example, pain associated with angina or tachycardia from atrial fibrillation, may contribute to greater limitations, or act as a constant reminder of the disease, and therefore exert a stronger influence on HRQoL. In contrast, conditions such as hypertension are of a more 'silent' or asymptomatic nature but could affect HRQoL via medications and their possible side effects. Furthermore, myocardial infarction patients may view their disease as a onetime occurrence that happened in the past. If patients recover fully, this may contribute to the disease having a lower impact on their HRQoL.

The findings of this study, that both the number of cardiovascular diseases and the subjective burden of disease, affect HRQoL, are important for the care of patients. It seems that patients' own perceptions of their disease, which might be different from a clinician's rating of their disease, have a strong influence on HRQoL. HRQoL assessments could be used as a helpful complement to a clinical assessment to give a comprehensive view of a patient's condition. ${ }^{21}$ The strong 
association between major burden of any cardiovascular disease and poor HRQoL, in particular poor physical function and symptomatic fatigue and dyspnoea supports the idea that HRQoL may reflect objective symptoms from cardiovascular disease. These findings suggest that a general question about the subjective burden of disease may be useful within the clinic, since patients reporting minor burden are less likely to suffer negative impact of the disease on their daily life, while those reporting major burden might need a more thorough review of the impact of their disease. However, further evaluation of the partial overlap between subjective ratings of burden and HRQoL is needed as a greater number of objective symptoms do not necessarily equate poor HRQoL since patients may prioritise other values or aspects or adopt coping strategies which may also influence HRQoL.

In conclusion, this large, population-based study of unselected people aged 40-79 years with and without cardiovascular diseases in the general Swedish population, indicates that people with several cardiovascular diseases and people reporting a subjective larger burden of cardiovascular diseases are at a substantially increased risk for poor HRQoL indicating a need for more intense follow-up and interventional care of their cardiovascular diseases.

Contributor All authors designed the study, contributed to analysis and interpretation of data, contributed to critical revision of the manuscript with important intellectual content and finally approved the version of manuscript to be submitted DT performed the statistical analysis, drafted the manuscript DT and LP contributed to acquisition of data and to administrative, technical and material support LP obtained funding and supervised the study.

Competing interest None.

Data sharing statement There are no additional data available.

Funding TD is supported by Karolinska Institute. AW is supported by the Swedish Research Council. PL is supported by the Swedish Research Council and the Swedish Cancer Society. The project was funded by the Swedish Research Council, the Swedish Cancer Society and the Cancer Society in Stockholm.

\section{REFERENCES}

1. Juenger J, Schellberg D, Kraemer S, et al. Health related quality of life in patients with congestive heart failure: comparison with other chronic diseases and relation to functional variables. Heart 2002;87:235-41.

2. Hobbs FD, Kenkre JE, Roalfe AK, et al. Impact of heart failure and left ventricular systolic dysfunction on quality of life: a cross-sectional study comparing common chronic cardiac and medical disorders and a representative adult population. Eur Heart $J$ 2002;23:1867-76.

3. de Visser $\mathrm{CL}$, Bilo HJ, Groenier $\mathrm{KH}$, et al. The influence of cardiovascular disease on quality of life in type 2 diabetics. Qual Life Res 2002;11:249-61.

4. Thompson DR, Roebuck A. The measurement of health-related quality of life in patients with coronary heart disease. J Cardiovasc Nurs 2001;16:28-33.

5. Oldridge N, Saner H, McGee HM. The Euro Cardio-QoL Project. An international study to develop a core heart disease health-related quality of life questionnaire, the HeartQoL. Eur J Cardiovasc Prev Rehabil 2005;12:87-94.

6. Schweikert B, Hunger M, Meisinger C, et al. Quality of life several years after myocardial infarction: comparing the MONICA/ KORA registry to the general population. Eur Heart $J$ 2009; 30:436-43.

7. Soto Torres M, Marquez Calderon S, Ramos Diaz I, et al. Health-related quality of life in coronary heart disease compared to norms in Spanish population. Qual Life Res 2004;13:1401-7.

8. Alonso J, Ferrer M, Gandek B, et al. Health-related quality of life associated with chronic conditions in eight countries: results from the International Quality of Life Assessment (IQOLA) Project. Qual Life Res 2004;13:283-98.

9. Brown N, Melville M, Gray D, et al. Quality of life four years after acute myocardial infarction: short form 36 scores compared with a normal population. Heart 1999;81:352-8.

10. Zellweger MJ, Osterwalder $\mathrm{RH}$, Langewitz W, et al. Coronary artery disease and depression. Eur Heart J 2004;25:3-9.

11. Wee HL, Cheung YB, Li SC, et al. The impact of diabetes mellitus and other chronic medical conditions on health-related quality of life: is the whole greater than the sum of its parts? Health Qual Life Outcomes 2005;3:2.

12. Kempen Gl, Ormel J, Brilman El, et al. Adaptive responses among Dutch elderly: the impact of eight chronic medical conditions on health-related quality of life. Am J Public Health 1997;87:38-44.

13. Aaronson NK, Ahmedzai S, Bergman B et al. The European Organization for Research and Treatment of Cancer QLQ-C30: a quality-of-life instrument for use in international clinical trials in oncology. J Natl Cancer Inst 1993;85:365-76.

14. Michelson $\mathrm{H}$, Bolund $\mathrm{C}$, Nilsson $\mathrm{B}$, et al. Health-related quality of life measured by the EORTC QLQ-C30-reference values from a large sample of Swedish population. Acta Oncol (Stockholm, Sweden) 2000;39:477-84.

15. Bradshaw PJ, Jamrozik KD, Gilfillan IS, et al. Asymptomatic long-term survivors of coronary artery bypass surgery enjoy a quality of life equal to the general population. Am Heart $J$ 2006;151:537-44

16. Beck CA, Joseph L, Belisle $P$, et al. Predictors of quality of life 6 months and 1 year after acute myocardial infarction. Am Heart $J$ 2001;142:271-9.

17. Garin O, Ferrer M, Pont A, et al. Disease-specific health-related quality of life questionnaires for heart failure: a systematic review with meta-analyses. Qual Life Res 2009;18:71-85.

18. Statistics Sweden. Populations statistics. http:// www.scb.se (accessed 1 Apr 2011)

19. The National Board of Health and Welfare in Sweden. Official webpage. Visited on 1 April 2011.

20. Chen HY, Baumgardner DJ, Rice JP. Health-related quality of life among adults with multiple chronic conditions in the United States, behavioral risk factor surveillance system. Prev Chronic Dis 2007;8:A09.

21. Calkins DR, Rubenstein LV, Cleary PD, et al. Failure of physicians to recognize functional disability in ambulatory patients. Ann Internal Med 1991;114:451-4. 